\title{
Economic Analysis on Value Chain of Taxi Fleet with Battery-Swapping Mode Using Multiobjective Genetic Algorithm
}

\author{
Guobao Ning, ${ }^{1}$ Zijian Zhen, ${ }^{2}$ Peng Wang, ${ }^{3}$ \\ Yang $L^{,}{ }^{4}$ and Huaixian Yin ${ }^{5}$ \\ ${ }^{1}$ School of Automotive Studies, Tongji University, No. 4800 Cao'an Road, Shanghai 201804, China \\ ${ }^{2}$ The High Technology Research and Development Center, No. 1 Sanlihe Road, Beijing 100044, China \\ ${ }^{3}$ China Automotive Engineering Research Institute Co., Ltd., Xinghuo Mansion, Fengtai District, \\ Beijing 100071, China \\ ${ }^{4}$ Potevio New Energy Co., Ltd., No. 6 Haidian North Second Street, Haidian District, \\ Beijing 100080, China \\ ${ }^{5}$ Qingdao University, No. 308 Ningxia Road, Qingdao 266071, China
}

Correspondence should be addressed to Guobao Ning, guobao_tj@163.com

Received 4 October 2012; Revised 27 November 2012; Accepted 27 November 2012

Academic Editor: Baozhen Yao

Copyright (C) 2012 Guobao Ning et al. This is an open access article distributed under the Creative Commons Attribution License, which permits unrestricted use, distribution, and reproduction in any medium, provided the original work is properly cited.

This paper presents an economic analysis model on value chain of taxi fleet with battery-swapping mode in a pilot city. In the model, economic benefits of charging-swapping station group, taxi company, and taxi driver in the region have been taken into consideration. Thus, the model is a multiobjective function and multiobjective genetic algorithm is used to solve this problem. According to the real data collected from the pilot city, the multiobjective genetic algorithm is tested as an effective method to solve this problem. Furthermore, the effects of price of electricity, price of battery package, life cycle of battery package, cost of battery-swapping devices and infrastructure, and driving mileage per day on the benefits of value holders are analyzed, which provide theoretical and practical reference for the deployment of electric vehicles, for the national subsidy criteria adjusment, technological innovation instruction, commercial mode selection, and infrastructure construction.

\section{Introduction}

Economic analysis on value chain of taxi fleet with battery-swapping mode in a pilot city is a basic condition for the sustainable commercialization of electric vehicle operations. Some factors, such as vehicle cost, life cycle of battery package, and reliability, are used to affect the benefits of the value holders. In addition, electricity price, cost of battery-swapping devices 
and infrastructure, and national subsidy criteria also have impacts on the benefits of all value holders as well as the sustainable commercial operation and popularization of electric vehicles. There is much more analysis on current status, policies, regional development, business models, and value chain management model of China electric vehicle demonstration operations [1-5]. However, these traditional methods have qualitatively analyzed current status, policies, regional development, business models, and value chain management model of China's electric vehicle demonstration operations. If an analyzed model can be proposed to provide the economic effect by quantitative analysis, it is very important to judge the feasibility of this project.

Many modeling approaches have been applied to evaluate the economic analysis. Hamilton [6] presented a method on the economic analysis to model the changes in regime which is based on the nonstationary time series and the business cycle. Aidt [7] provided an economic analysis which considered the notion of a benevolent principal as a normative theory of corruption.

To represent the economic analysis on value, the competitive nature about these factors has occurred as a result of parallel development in the application of taxi fleet with batteryswapping. In this paper, the model consists of three parts. One is empirical model of monthly operating benefits of charging-swapping station group in the region, another is empirical model of monthly operating benefits of taxi fleet company, and the third is empirical model of monthly operating benefits of taxi fleet drivers. To reflect the effect of these factors which will directly determine the effectiveness of the new project, the electricity price, battery package price, battery package, battery-swapping devices, infrastructure, and driving mileage per day need to be discussed. Thus, this paper took some pilot cities as an example and established a multiobjective model which is attempted to optimize the economic analysis on value chain of taxi fleet with battery-swapping mode in some pilot cities with a multiobjective model which can describe the economic analysis from different aims.

Taxi fleet with battery-swapping mode in real world, which is related to large of factors, is inefficient to be solved by classical optimization techniques and belongs to a class of problems referred to as nondeterministic polynomial-time hard (NP-hard) [8]. Generally, heuristics are considered as a first choice to solving these combinatorial optimization problems [9-11]. Genetic algorithm [12], which is a multipurpose optimization tool, has successfully been applied in a wide range of optimization problems [13, 14]. Furthermore, GA has been used widely in transportation fields [15-17]. Altiparmak et al. [18] proposed a genetic algorithm to find the solutions for multi-objective supply chain networks. Due to many successful results of combination optimization applications with GA, GA is also used to optimize this taxi fleet with battery-swapping economic mode in this paper.

Some studies have attempted for designing multi-objective genetic algorithms since Schaffer [19]. There are also much literature about multi-objective genetic algorithm for solving lots of complicated problems. Mansouri [20] proposed a multi-objective genetic algorithm to solve a just-in-time sequencing problem, in which the variation of production rates and the number of setups has been optimized simultaneously. Cochran et al. [21] introduced a multi-objective genetic algorithm with a two-stage for solving parallel machine scheduling problems. Ponnambalam et al. [22] proposed a multi-objective genetic algorithm for solving assembly line balancing problems, where the number of workstations, the line efficiency, and the smoothness index are considered as the performance criteria.

Since economic analysis on value chain of taxi fleet with battery-swapping mode is a multi-objective mode, a multi-objective genetic algorithm is also attempted for solving the mode. Thus, this paper is organized in the following way: Section 2 is about the problem of 
the basic notations and formulations; Section 3 contains a multi-objective genetic algorithm for the problem; numerical analysis is carried out in Section 4; and, lastly, the conclusions are drawn in Section 5.

\section{Economic Benefits Analysis on Taxi Fleet Demonstration with Battery-Swapping Mode}

\subsection{Empirical Model of Monthly Operating Benefits of Charging-Swapping Station Group in the Region}

Our main contribution is to design empirical model of monthly operating benefits of charging-swapping station group in the region. Therefore, before the model is established, we assume the following:

(1) in order to meet the normal operation of the taxi fleet, a charging-swapping station group should be constructed in some demonstration area after comprehensive consideration of various conditions, which is operated by $n_{s}$ charging-swapping stations in a network and ensures the normal operation of the taxi fleet in the region;

(2) charging-swapping station group is responsible for the purchase of battery pack assembled on taxi vehicles; each vehicle can only be fitted with one battery pack at the same time, which is constituted by a number of subpacks;

(3) all the other costs are ignored except the expenditure and income listed by the empirical model of operating benefits of charging-swapping station group in the region;

(4) the cost of charge is charged according to vehicles mileage of the taxi fleet by the charging-swapping station group in the region.

The monthly operating benefits of charging-swapping station group in the region $B_{0}$ equals the monthly total income of charging-swapping station group in the region $B_{\mathrm{st}}$ minus the monthly total expenditure of charging-swapping station group in the region $C_{S}$, that is, $B_{o}=$ $B_{\mathrm{st}}-C_{s}$.

The monthly total income of charging-swapping station group in the region is calculated as

$$
B_{\mathrm{st}}=\sum_{i=1}^{n_{\mathrm{s}}} B_{\mathrm{si}}
$$

in which $B_{\mathrm{st}}$ : total income of charging-swapping station group, unit: yuan; $B_{\mathrm{si}}$ : monthly income of the $i$ th charging-swapping station in the group, unit: yuan; $N_{s}$ : the total number of the charging-swapping station in the group; $i$ : the number of the charging-swapping station. Consider

$$
B_{\mathrm{si}}=\sum_{v=1}^{n_{v}} C \times R_{\mathrm{vm}}
$$

$C$ : the charges per kilometer which is agreed by the charging-swapping station group and the owner of thevehicle, unit: yuan/kilometer; $R_{\mathrm{vm}}$ : the monthly mileage of a vehicle; 
$B_{\mathrm{vm}}=\sum_{d=1}^{30} R_{\mathrm{vmd}}$, unit: kilometer, $R_{\mathrm{vmd}}$ : the daily mileage of a vehicle, $n_{v}$ : the total number of the vehicles which is served by the charging-swapping station group.

The monthly total expenditure of charging-swapping station group in the region is calculated as

$$
C_{s}=C_{d}+C_{p}+C_{b}+C_{e}
$$

in which $C_{d}$ : total cost of the initial construction of the charging-swapping station group in the region converted to monthly $\operatorname{cost} C_{\mathrm{dc}}$ and monthly costs for facilities and equipment maintenance $C_{\mathrm{dv}}$, unit: yuan/month,

$$
C_{d}=C_{\mathrm{dc}}+C_{\mathrm{dv}}, \quad C_{\mathrm{dc}}=\frac{C_{\mathrm{bc}} / Y_{c}}{12}, \quad C_{\mathrm{dv}}=C_{\mathrm{bc}} \times D_{\mathrm{de}}
$$

$C_{\mathrm{bc}}$ : the total cost of the initial construction of the charging-swapping station group in the region; $D_{\mathrm{de}}$ : the depreciation rate of the facilities and equipment of the charging-swapping station group in the region, $Y_{c}$ : the useful lives or the depreciation period of the facilities and equipment of the charging-swapping station group in the region, $C_{p}$ : the total monthly salaries of the professional services staffs of the charging-swapping station group, $C_{p}=$ $C_{\mathrm{pp}} \times N_{\mathrm{ps}}$, unit: yuan; $C_{\mathrm{pp}}$ : the personal average monthly salary of the professional services staffs of the charging-swapping station group, unit: yuan; $N_{\mathrm{ps}}$ : the number of the professional services staffs of the charging-swapping station group. $C_{b}$ : The monthly depreciation cost of the charging-swapping station group. Consider

$$
C_{b}=\frac{\left(R_{\mathrm{bn}} \times n_{v} \times P_{\mathrm{bp}}-n_{v} \times P_{\mathrm{gb}}\right)}{Y_{\mathrm{bp}} / 12},
$$

$Y_{\mathrm{bp}}$ : the useful lives or the depreciation period of battery package and $R_{\mathrm{bn}}$ : the number of battery package of each vehicle, $R_{\mathrm{bn}}=\left(R_{\mathrm{vm}} \times 12 \times Y_{v}\right) /\left(\left(C_{\mathrm{bpc}} / C_{\mathrm{per} \mathrm{km}}\right) \times N_{\mathrm{cy}}\right)$, which is influenced by the charging time of the battery. In order to ensure the normal operation of vehicles, $R_{\mathrm{bn}} \geq 3, Y_{v}$ : the useful lives or the depreciation period of vehicles; according to the relevant laws and regulations, $Y_{v}$ should meet the conditions $Y_{v} \leq 600000 /\left(R_{\mathrm{vm}} \times 12\right)$ and $Y_{v} \leq 8$ at the same time. (According to mandatory retirement standard of motor vehicle, if the taxi's total mileage is more than $600000 \mathrm{~km}$, or it has been used for more than 8 years, then it must be scrapped.) $C_{\mathrm{bpc}}$ : available power for driving of each battery package, unit: $\mathrm{kWh}$; $C_{\text {per km}}$ : the average consumption level of driving, unit: $\mathrm{kWh} / \mathrm{km} ; N_{\text {cy }}$ of battery package; unit: time; $P_{\mathrm{bp}}$ : the price of each battery package, unit: yuan; $P_{\mathrm{gb}}$ : state subsidies standards of each battery package, unit: yuan; $C_{e}$ : monthly charges for electricity paid to the electric power provider by the charging-swapping station group, $P_{\mathrm{el}}$ : actual price of $\mathrm{AC}$, unit: yuan $/ \mathrm{kWh}$; $\eta$ : the charging efficiency of the battery package.

Thus, the objective function of the monthly operating benefits of charging-swapping station group in the region can be described as the following:

$$
\operatorname{Max} B_{0}=B_{\text {st }}-C_{s} \text {. }
$$




\subsection{Empirical Model of Monthly Operating Benefits of Taxi Fleet Company}

Our main contribution is to design empirical model of monthly operating benefits of taxi fleet company. Therefore, before the model is established, we assume the following:

(1) the income of taxi fleet company only come from the fee paid by all vehicles in the fleet;

(2) every taxi has one driver;

(3) all the other costs are ignored except the expenditure and income listed in the empirical model of the operating benefits of the taxi fleet company.

Then, the operating benefits of the taxi fleet company equals the difference between the monthly fee paid to the taxi fleet by all vehicles $B_{\text {st }}$ and the monthly total operating expenditures of all the vehicles in the company $C_{\mathrm{cs}}$, that is, $B_{\mathrm{co}}=B_{\mathrm{cst}}-C_{\mathrm{cs}}$,

$$
C_{\mathrm{cs}}=C_{\mathrm{vs}}+C_{\mathrm{es}}+C_{\mathrm{ps}}+C_{\mathrm{ma}}
$$

in which $C_{\mathrm{cs}}$ : monthly total operating expenditures of all the vehicles in the company, unit: yuan; $B_{\mathrm{cst}}$ : monthly fee paid to the taxi fleet company by all vehicles, namely, $B_{\mathrm{cst}}=C_{c} \times n_{v}$, unit: yuan; $C_{c}$ : monthly fee paid to the taxi fleet company per driver, $C_{c}=\sum_{d=1}^{30} C_{\mathrm{dds}}$, unit: yuan; $C_{\mathrm{dds}}$ : daily fee paid to the taxi fleet company per driver, unit: yuan; $C_{\mathrm{vs}}$ : total car cost of all vehicles in the fleet bare (excluding battery pack) converted to monthly operational expenses, $C_{\mathrm{vs}}=P_{v} \times n_{v} / Y_{v} / 12$, unit: yuan; $P_{v}$ : initial acquisition cost per vehicle (excluding the battery package), unit: yuan; $C_{\mathrm{es}}$ : insurance cost of all the vehicles in the fleet converted to monthly operational expenses, $C_{\mathrm{es}}=\sum_{n=1}^{n_{v}}\left(C_{\mathrm{en}} / 12\right) ; C_{\mathrm{en}}$ : insurance cost standards per year per vehicle, unit: yuan; $C_{\mathrm{ps}}$ : fixed remuneration expenditure for all taxi drivers in the fleet, $C_{\mathrm{ps}}=\sum_{n=1}^{n_{v}} S_{\mathrm{pp}} ; S_{\mathrm{pp}}$ : fixed remuneration expenditure per driver per month, unit: yuan; $C_{\mathrm{ma}}$ : monthly maintenance fee for all the vehicles in the fleet, $C_{\text {ma }}=\sum_{n=1}^{n_{v}} C_{\text {ma per, }}$, unit: yuan; $C_{\text {maper }}$ : Monthly maintenance fee per vehicle in the fleet, unit: ypuan.

Thus, the objective function of monthly operating benefits of taxi fleet company can be described as the following:

$$
\operatorname{Max} B_{\mathrm{co}}=B_{\mathrm{cst}}-C_{\mathrm{cs}} \text {. }
$$

\subsection{Empirical Model of Monthly Operating Benefits of Taxi Fleet Drivers}

The monthly average operating benefits of new energy taxi fleet drivers $B_{\mathrm{do}}$, in which the income equals the monthly average earnings per vehicle $B_{\mathrm{ds}}$ and the fixed salary paid by taxi fleet company $S_{\mathrm{pp}}$ and its expenses include the monthly fee paid to the taxi fleet company $C_{c}$ and the average monthly charge fee paid to the charging-swapping station group in the region $C_{\mathrm{de}}$, is calculated as

$$
B_{\mathrm{do}}=B_{\mathrm{ds}}+S_{\mathrm{pp}}-C_{c}-C_{\mathrm{de}}
$$

in which $B_{\mathrm{ds}}$ : monthly earnings per vehicle, $B_{\mathrm{ds}}=\sum_{d=1}^{30} B_{\mathrm{pt}} \times T_{\mathrm{pv}}$, unit: yuan; $B_{\mathrm{pt}}$ : the charges paid by passengers per time, unit: yuan; $T_{\mathrm{pv}}$ : the number of service provided by a vehicle per 
day; $C_{\mathrm{de}}$ : the monthly charge fee paid to the charging-swapping station group in the region, namely, $C_{\mathrm{de}}=C \times R_{\mathrm{vm}}$, unit: yuan.

Thus, the objective function of monthly operating benefits of taxi fleet company can be described as the following:

$$
\operatorname{Max} B_{\mathrm{do}}=B_{\mathrm{ds}}+S_{\mathrm{pp}}-C_{c}-C_{\mathrm{de}}
$$

\subsection{Economic Efficiency Model of Taxi Fleet with Battery-Swapping}

The region, company, and taxi driver are three different aspects which are directly affected by the new taxi fleet with battery-swapping. To meet the benefits of all the three aspects, the three objective functions should be considered simultaneously. Thus, the economic efficiency model of taxi fleet with battery-swapping is constructed to achieve the following three objectives:

$$
\begin{aligned}
& \operatorname{Max} B_{\mathrm{st}} \\
& \operatorname{Max} B_{\mathrm{co}} \\
& \operatorname{Max} B_{\mathrm{do}}
\end{aligned}
$$

\section{Applying Multiobjective GA for the Economic Efficiency Model of Taxi Fleet with Battery-Swapping Mode}

\subsection{Initialization}

The initialization of the population is generated randomly according to some certain constraints to ensure the feasibility of each population.

\subsection{Fitness}

The difference between traditional genetic algorithm and multi-objective genetic algorithm is the number of objective functions. The economic efficiency model of taxi fleet with batteryswapping has three objective functions. For each target $i$, there is an evolution based on the merits of the objective function value and a feasible solution is attained. Then, based on all objectives, the total fitness of each solution can be also attained. The total fitness can be acquired according to the following:

$$
\begin{aligned}
& f_{i}\left(x_{j}\right)= \begin{cases}\left(N+1-y_{i}\left(x_{j}\right)\right)^{2} & y_{i}\left(x_{j}\right)>1, \\
k N^{2} & y_{i}\left(x_{j}\right)=1,\end{cases} \\
& f\left(x_{j}\right)=\sum_{i=1}^{n} f_{i}\left(x_{j}\right) \quad j=1,2, \ldots, n,
\end{aligned}
$$

where $N$ is the sum of all the individual, $x_{j}$ denotes the $j$ th individual, $y_{i}$ denotes the number of all the individuals on the objective $i . f_{i}\left(x_{j}\right)$ is the fitness of $x_{j}$ based on the objective $i$. 
$\sum_{i=1}^{n} f_{i}\left(x_{j}\right)$ is the synthesized fitness of $x_{j}$ based on all the objectives. $k$ is the random number in $(1,2)$, which is used to adjust the weight of the fitness.

If there are four chromosomes $\left(g_{1}, g_{2}, g_{3}, g_{4}\right)$, their objective values based on three objectives are $(1.6,0,1.4),(1.8,0.6,2.6),(2,1,2)$, and $(2.1,2.5,3.2)$. To prevent the increase of an individual to reduce the opportunity of other individual, $k=1.01$. Then, to the objective 1 , the fitness is $(1,4,9,16.16)$ and the order is $\left(g_{1}<g_{2}<g_{3}<g_{4}\right)$. To the objective 2 , the fitness is $(16.16,9,4,1)$ and the order is $\left(g_{1}>g_{2}>g_{3}>g_{4}\right)$. To the objective 3 , the order is $\left(g_{1}>g_{2}>g_{3}>g_{4}\right)$. To the objective 4 , the order is $\left(g_{1}>g_{3}>g_{4}>g_{2}\right)$. According to (3.1), $g_{1}$ has the maximum fitness value.

\subsection{Crossover Operation}

Crossover is a reproduction operation in GA, which is exchanging genetic information between two parent chromosomes to produce two new children. In the paper, an arithmetic crossover [23] is used to create new offsprings.

$$
\begin{gathered}
g_{k, I}^{t}=\alpha_{i} g_{k, I}^{t-1}+\left(1-\alpha_{k}\right) g_{k, I I}^{t-1} \\
g_{k, I I}^{t}=\alpha_{i} g_{k, I I}^{t-1}+\left(1-\alpha_{k}\right) g_{k, I}^{t-1}
\end{gathered}
$$

where $g_{k, I}^{t-1}, g_{k, I I}^{t-1}$ is a pair of "parent" chromosomes; $g_{k, I}^{t} g_{k, I I}^{t}$ is a pair of "children" chromosomes; $\alpha_{k}$ is a random number between $(0,1) ; k \in[1,2,3]$ ( $k$ is the total genes for the crossover operation).

\subsection{Mutation Operation}

Mutation is also a reproduction operation in GA, which is applied with a mutation rate to avoid being trapped in local optimal during evolution. Assume that a chromosome is $G=$ $\left(g_{1}^{t}, g_{2}^{t}, g_{3}^{t}\right)$, if the $g_{2}^{t}$ was selected for the mutation, the mutation can be shown in (3.3):

$$
\begin{gathered}
G^{\prime}=\left(g_{1}^{t-1}, g_{2}^{t}, g_{3}^{t-1}\right) \\
g_{2}^{t}= \begin{cases}g_{2}^{t-1}+\Delta\left(t, g_{2 \max }^{t}-g_{2}^{t-1}\right) & \text { if random }(0,1)=0 \\
g_{2}^{t-1}+\Delta\left(t, g_{2}^{t-1}-g_{2 \min }^{t}\right) & \text { if random }(0,1)=1\end{cases}
\end{gathered}
$$

The function $\Delta(t, y)$ retains a value between $[0, y]$ given in the following:

$$
\Delta(t, y)=y \times\left(1-r^{\left(1-t / T_{\max }\right)^{\lambda}}\right),
$$

where $r$ is a random number between $[0,1] ; T_{\max }$ is maximum number of generations; here $\lambda=3$. This property causes this operation to make a uniform search in the initial space when $t$ is small and a very local one in later stages. 


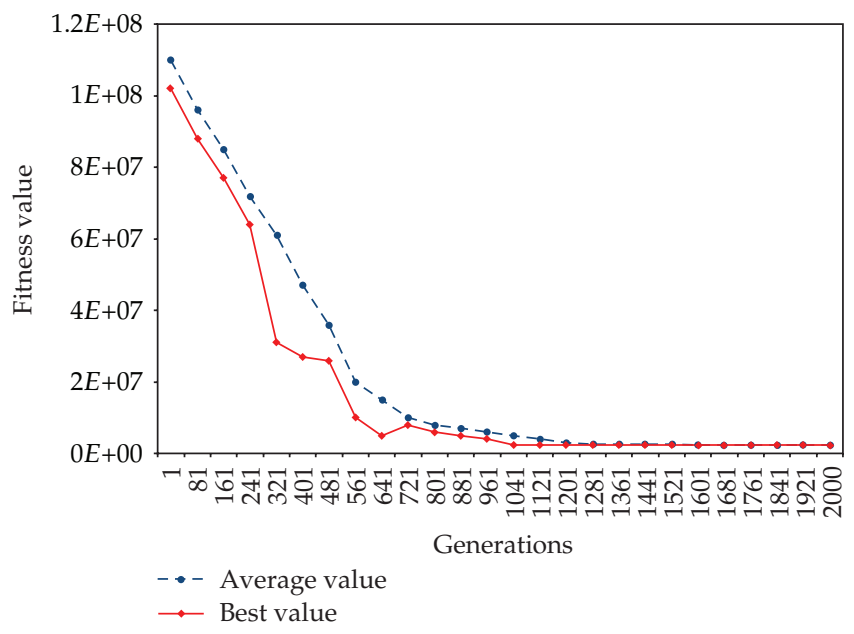

Figure 1: The computing process of GA.

\subsection{Termination}

In this paper, the search continues until $\mathrm{RMSE}_{n}-\mathrm{RMSE}_{n-1}<0.0001$ or the number of generation reaches the maximum number of generations $T_{\max }$.

\section{Numerical Test}

\subsection{Model Calibration}

GA is used to optimize the multi-objective mode of this paper. Before the implementation of GA, there are four parameters for GA, namely, $p_{c}, p_{m}, p_{\text {size, }}$ and $T_{\max }$, that need to be predetermined. Generally, $p_{c}$ varies from 0.3 to 0.9 . $p_{m}$ varies from 0.01 to $0.1, p_{\text {size }}$ is the population size which is set according to the size of the samples. $T_{\max }$ is the maximum number of generation which can be determined according to a good convergence of the calculation [24]. According the characteristic of this problem, the values of the four parameters $\left(p_{c}, p_{m}, p_{\text {size }}\right.$ and $\left.T_{\max }\right)$ are set as $0.65,0.1,80$, and 2000 , respectively.

The actual value of the problem in the model is collected in Table 1 based on the model operational data of the battery-swapping mode fleet and infrastructure collected from the pilot cities. Take 200 taxies in a region as an example, the GA reached convergence on the 1361 generation (Figure 1), and the results are shown as the following.

The profit of the taxi fleet company, operators of the infrastructure, and drivers of the taxi fleet company is shown in Figure 2. Through analysis the following conclusion is made: the early-stage construction cost of the charging-swapping stations distributed to individual vehicles is excessively high due to the relatively large investment in local chargingswapping stations and small number of vehicles served by the charging-swapping stations. Consequently, the groups involved in the value chain of fleet demonstration of taxi fleet are suffering serious financial loss, especially for the charging-swapping electricity stations. 
Table 1: The information of the instances.

\begin{tabular}{lc}
\hline Parameter & Value \\
\hline$n_{v}$ & 30 \\
$C$ & 0.75 \\
$R_{\mathrm{vmd}}$ & 428 \\
$C_{\mathrm{bc}}$ & $14,400,000$ \\
$D_{\mathrm{de}}$ & 0.03 \\
$Y_{c}$ & 10 \\
$N_{\mathrm{pa}}$ & 21 \\
$C_{\mathrm{pp}}$ & 3000 \\
$Y_{\mathrm{bp}}$ & 5 \\
$Y_{\mathrm{v}}$ & 3.8 \\
$C_{\mathrm{bpc}}$ & 12.5 \\
$C_{\mathrm{per} \text { km }}$ & 0.157 \\
$N_{\mathrm{cy}}$ & 1500 \\
$P_{\mathrm{bp}}$ & 75000 \\
$P_{\mathrm{gb}}$ & 60000 \\
$P_{\mathrm{el}}$ & 0.538 \\
$\eta$ & 0.8 \\
$C_{\mathrm{dds}}$ & 280 \\
$P_{v}$ & 150000 \\
$C_{\mathrm{en}}$ & 10000 \\
$S_{\mathrm{pp}}$ & 2800 \\
$C_{\mathrm{maper}}$ & 800 \\
$B_{\mathrm{pt}}$ & 16 \\
$T_{\mathrm{pv}}$ & 55 \\
\hline Note: $T_{\mathrm{pv}}$ Approximately increases \\
with $R_{\mathrm{vmd}}$ in proportion. \\
${ }_{\mathrm{p}}$ &
\end{tabular}

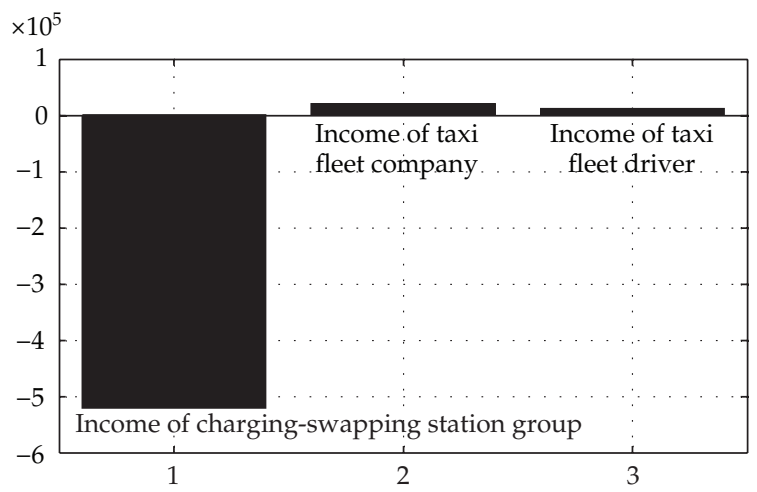

Figure 2: The profit of groups involved in the value chain of fleet demonstration of new energy taxi. 


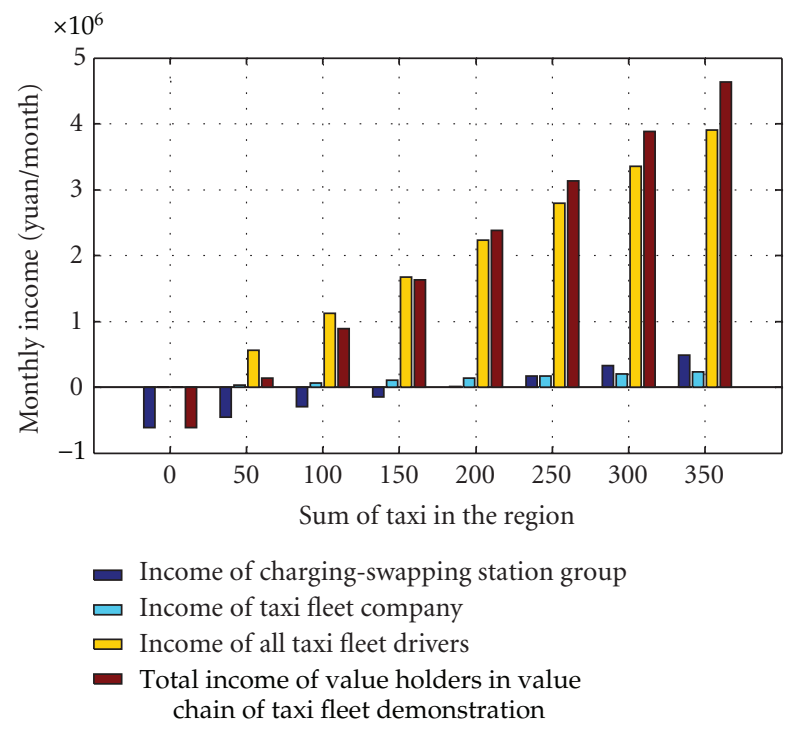

Figure 3: Influence of the total number of vehicles on the profit situation.

\subsection{Analysis on the Factors Influencing the Operation Profit}

\subsubsection{The Operational Load Rate of the Local Charging/Swapping Stations}

The service frequency is improved with the operating efficiency of charging-swapping station, which leads to the increase in the total number of taxis sharing the service. Figure 3 illustrates the profit variation of the value holders in the taxi fleet operation value chain in the case of a rising operation load (i.e., the total number of the taxi fleet vehicles that enjoy the service) of the local charging/swapping stations. Analysis manifests that the profit of taxi fleet company and the local charging/swapping stations grows as the operation load rises and the total profit increment of taxi drivers is proportional to that of the number of taxis. The total gain of the value holders in the value chain is positive when the scale of the fleet is close to 50 vehicles.

\subsubsection{Early-Stage Construction Cost of the Local Charging/Swapping Stations}

Refer to Figure 4 for the influence of early-stage construction cost of the local chargingswapping electricity stations on the total profit of value holders involved in the value chain of new energy taxi fleet demonstration. It is clear that the profit of the local charging-swapping electricity stations diminishes drastically as the early-stage investment cost increases; the total profit of value holders involved in the value chain appear negative when the investment scale exceeds certain extent.

\subsubsection{Lifespan of Battery Packages}

The curve in Figure 5 illustrates the individual and total profit of value holders involved in the value chain of fleet demonstration. It can be seen that lengthened lifespan of battery 


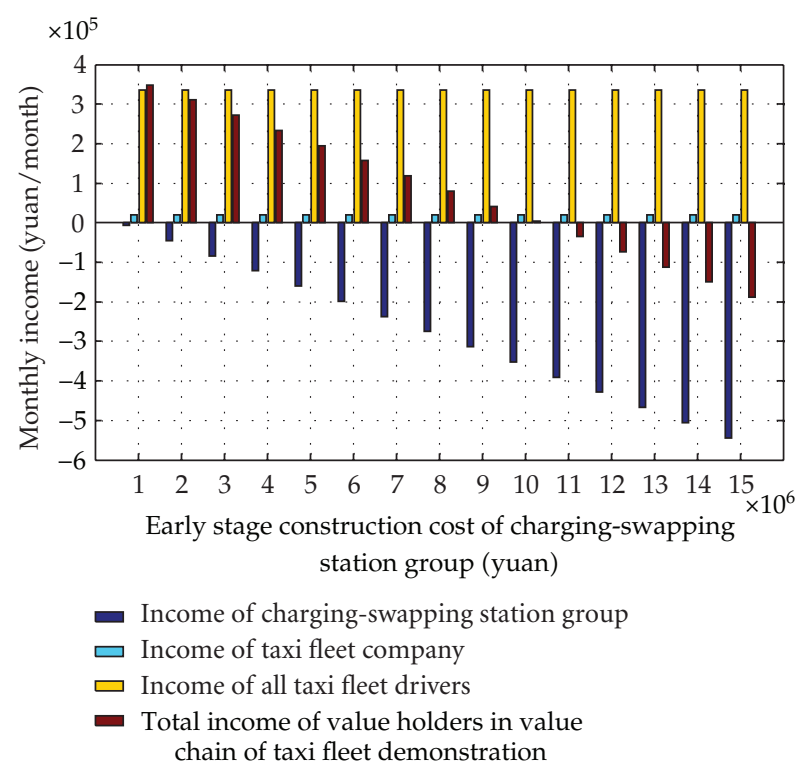

Figure 4: Influence of early stage investment cost of local charging-swapping electricity stations on profit.

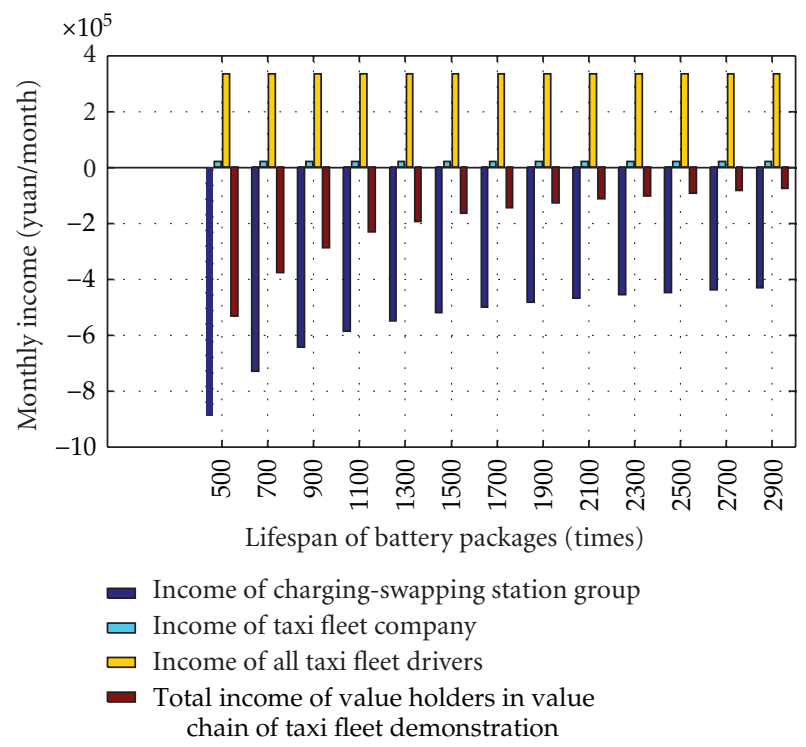

Figure 5: Influence of lifespan of battery packages on profit.

package leads to increment in the overall effectiveness of the charging/swapping stations in the value chain of new energy taxi fleet demonstration and thus the total profit of all the value holders. 


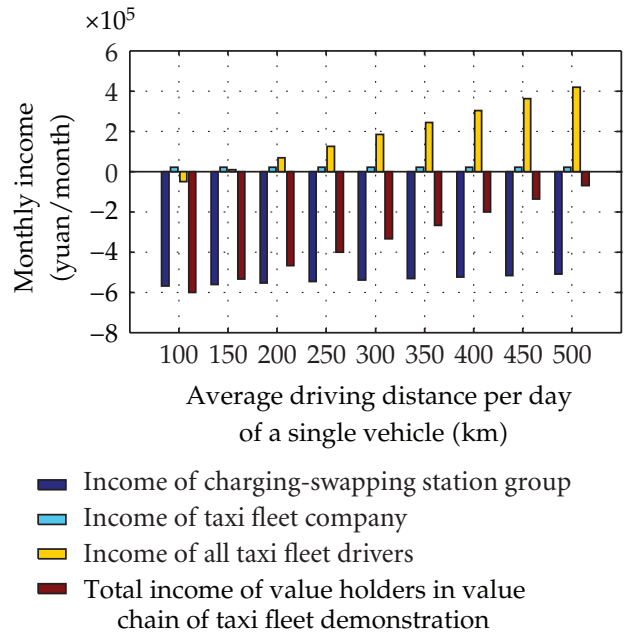

(a) Scale of taxi fleet: 30
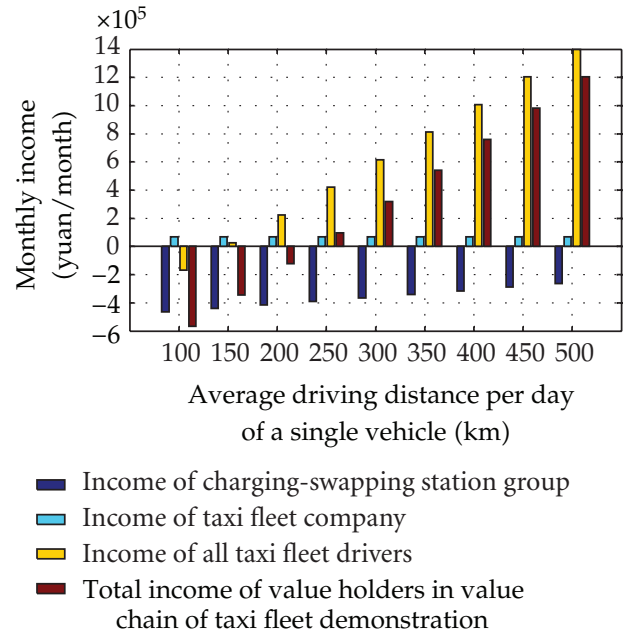

(b) Scale of taxi fleet: 100

Figure 6: The variation of profit of the value holders involved in the value chain of fleet demonstration with the average driving distance per day of a single vehicle.

\subsubsection{The Average Driving Distance per Day of a Single Vehicle}

To acquire the effect of the average driving distance per day of a single vehicle, the variation of profit of the value holders involved in the value chain of fleet demonstration with the average driving distance per day of a single vehicle can be shown in Figure 6.

It can be found in Figure 6 that the influence of average driving distance per day of a single vehicle on the profit of the value holders involved in the value chain of fleet demonstration. Analysis suggests that when the fleet is of a small-scale, the profit of taxi fleet drivers grows significantly as the daily driving distance increases whilst the earnings of the local charging/swapping stations remain negative but the amount of losses decrease gradually. Comparing Figures 6(a) and 6(b) yields the following: the total profit of the value holders involved in the value chain of fleet demonstration increases with average driving distance per day of a single vehicle; as the scale of the fleet is enlarged, it is possible for the value holders to make profit at an earlier stage and the total profit relies less on the daily driving distance.

\subsubsection{Price of Battery Packages}

The influence of price of battery package on profit can be attained in Figure 7. It can be seen that Figure 7 illustrates the influence of the price of battery package on the profit of the value holders involved in the value chain of fleet demonstration. Analysis indicates that increment in the price of battery leads to diminished profit of the local charging/swapping stations and the total profit of the value holders involved in the model value chain.

\subsubsection{Electricity Price}

Figure 8 shows the influence of electricity price on the value holders in the value chain of fleet demonstration. Analysis indicates that the total profit of the local charging/swapping 


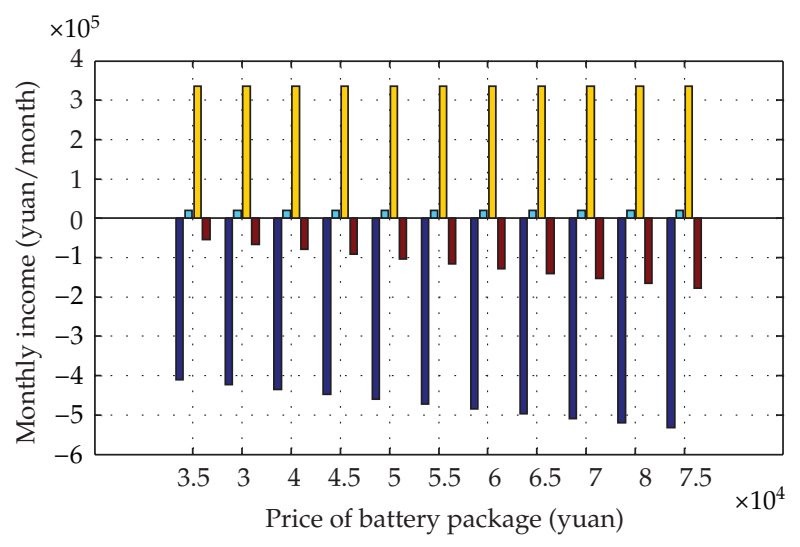

- Income of charging-swapping station group

$\square$ Income of taxi fleet company

$\square$ Income of all taxi fleet drivers

- Total income of value holders in value chain of taxi fleet demonstration

Figure 7: Influence of price of battery package on profit.

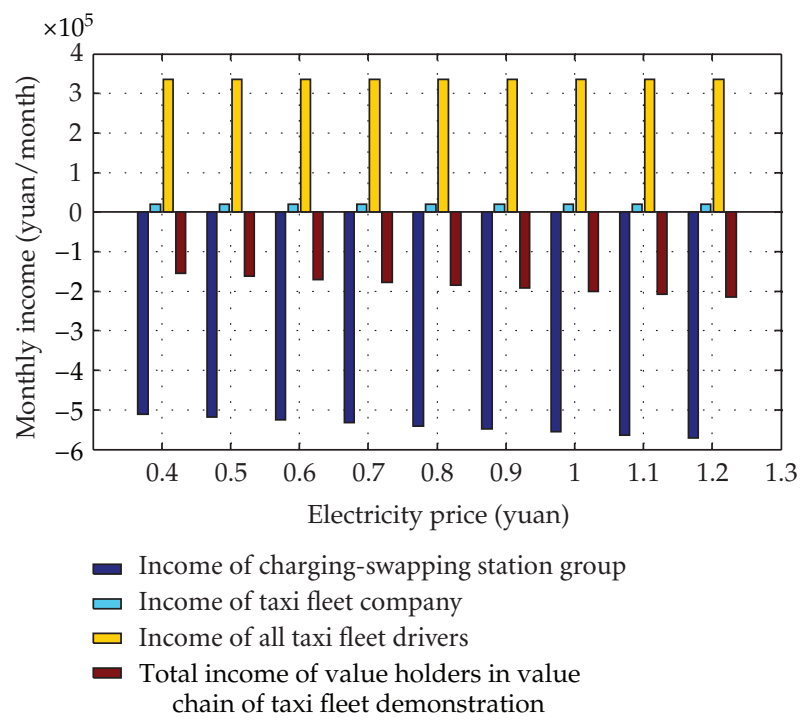

Figure 8: Influence of electricity price on profit.

stations as well as the total profit of the value holders in the model operation value is reduced as the electricity price given by the electricity supplier rises.

\section{Conclusions}

The verified demonstration operation economic benefit models of changing/swapping taxi fleet are solved by a multi-objective genetic algorithm. The influence of various factors on the individual profit and total profit of the value holders involved in the value chain of fleet 
demonstration of taxi fleet, such as electricity price, lifespan and price of battery package, construction cost of infrastructure, and driving mileage per day are summarized as the following.

The total profit of the value holders involved in the value chain of taxi fleet demonstration based on battery-swapping mode decreases as the electricity price rises. As the price of battery packages at the early stage rises, the profit of the local battery chargingswapping electricity groups decreases and thus the total profit of the value holders. With the advances in battery technologies and lengthened lifespan of battery packages, the benefits of the local charging/swapping stations increase significantly, which results in the enlarged total profit of value holders in value chain of the taxi fleet demonstration.

In the case that the taxi fleet is relatively small, as the driving mileage per day (usage rate) increases, the profit of taxi fleet drivers grows whilst the local charging/swapping stations remain losing money but with decreasing financial loss. The total profit of the value holders in the value chain of fleet demonstration grows with driving mileage of individual vehicles per day; as the scale of fleet is enlarged, the total profit of the value holders in the value chain of fleet demonstration is able to make profit at an earlier stage with total profit relying less on driving mileage per day. As operation load rate of the local chargingswapping electricity stations rises, the profit of the new taxi fleet company and suppliers of infrastructure grows and the profit of taxi fleet drivers increases proportionally with the number of taxis.

All value holders are able to make profit when the fleet scale is sufficiently large. The total profit of value holders in value chain of the new energy taxi fleet demonstration can be promoted effectively by adapting low-cost charging-swapping infrastructure, lowering battery price, lengthening the lifespan of battery, and raising the operation efficiency of charging-swapping stations.

\section{References}

[1] K. Chen, Z. P. Wang, and C. Lin, "Development and demonstration of pure electric vehicle in Beijing," New Materials Industry, no. 9, pp. 27-30, 2006.

[2] X. Fu and B. X. Hu, "Wang Y.N. Current Situation of demonstration operations and policy research of the electric vehicle in Wuhan," Shanghai Automobile, no. 6, pp. 9-12, 2007.

[3] F. X. Dai, "Research of demonstration operation's development strategy facing the industrialization of electric vehicle," Technology Development and Policy, vol. 26, no. 16, pp. 71-73, 2009.

[4] F. Q. Zhao and Y. Chen, "Strategy of geographic expansion of electric vehicle demonstration operations based on scale economy," Modern Management Science, no. 10, pp. 82-83, 2008.

[5] Q. Deng, L. M. Zhu, and Y. N. Tang, "Analysis on demonstration operations of parallel hybrid city bus XD6120HEV of XEMC," Urban Vehicle, no. 2, pp. 55-58, 2008.

[6] J. D. Hamilton, "Many modeling approaches have been applied to evaluate the economic analysis," Econometrica, vol. 57, no. 2, pp. 357-384, 1989.

[7] T. S. Aidt, "Economic analysis of corruption: a survey," Economic Journal, vol. 113, no. 491, pp. F632F652, 2003.

[8] A. Haghani, M. Banishashemi, and K. H. Chiang, "A comparative analysis of bus transit vehicle scheduling models," Transportation Research B, vol. 37, no. 4, pp. 301-322, 2003.

[9] B. Yu and Z. Z. Yang, "An ant colony optimization model: the period vehicle routing problem with time windows," Transportation Research E, vol. 47, no. 2, pp. 166-181, 2011.

[10] B. Yu, Z. Z. Yang, and B. Yao, "An improved ant colony optimization for vehicle routing problem," European Journal of Operational Research, vol. 196, no. 1, pp. 171-176, 2009.

[11] B. Yu, Z.-Z. Yang, and S. Li, "Real-time partway deadheading strategy based on transit service reliability assessment," Transportation Research A, vol. 46, no. 8, pp. 1265-1279, 2012.

[12] J. H. Holland, Adaptation in Natural and Artificial Systems, University of Michigan Press, Ann Arbor, Mich, USA, 1975. 
[13] D. E. Goldberg, Genetic Algorithms in Search, Optimization, and Machine Learning, Addison-Wesley, 1989.

[14] L. D. Chambers, Practical Handbook of Genetic Algorithms: New Frontiers, CRC Press, Boca Raton Fla USA, 1995.

[15] A. Wren and D. O. Wren, "A genetic algorithm for public transport driver scheduling," Computers and Operations Research, vol. 22, no. 1, pp. 101-110, 1995.

[16] P. Chakroborty, K. Deb, and P. S. Subrahmanyam, "Optimal scheduling of urban transit systems using genetic algorithms," Journal of Transportation Engineering, vol. 121, no. 6, pp. 544-553, 1995.

[17] P. Chakroborty, "Genetic algorithms for optimal urban transit network design," Computer-Aided Civil and Infrastructure Engineering, vol. 18, no. 3, pp. 184-200, 2003.

[18] F. Altiparmak, M. Gen, L. Lin, and T. Paksoy, "A genetic algorithm approach for multi-objective optimization of supply chain networks," Computers and Industrial Engineering, vol. 51, no. 1, pp. 196$215,2006$.

[19] J. D. Schaffer, "Multiple objective optimization with vector evaluated genetic algorithms," in Proceedings of the 1st International Conference on Genetic Algorithms (ICGA '85), pp. 93-100, 1985.

[20] S. A. Mansouri, "A multi-objective genetic algorithm for mixed-model sequencing on JIT assembly lines," European Journal of Operational Research, vol. 167, no. 3, pp. 696-716, 2005.

[21] J. K. Cochran, S.-M. Horng, and J. W. Fowler, "A multi-population genetic algorithm to solve multiobjective scheduling problems for parallel machines," Computers $\mathcal{E}$ Operations Research, vol. 30, no. 7, pp. 1087-1102, 2003.

[22] S. G. Ponnambalam, P. Aravindan, and G. Mogileeswar Naidu, “Multi-objective genetic algorithm for solving assembly line balancing problem," International Journal of Advanced Manufacturing Technology, vol. 16, no. 5, pp. 341-352, 2000.

[23] B. Yu, Z. Yang, and C. Cheng, "Optimizing the distribution of shopping centers with parallel genetic algorithm," Engineering Applications of Artificial Intelligence, vol. 20, no. 2, pp. 215-223, 2007.

[24] B. Yu, Z. Z. Yang, P. H. Jin, S. H. Wu, and B. Z. Yao, “Transit route network design-maximizing direct and transfer demand density," Transportation Research C, vol. 22, pp. 58-75, 2012. 


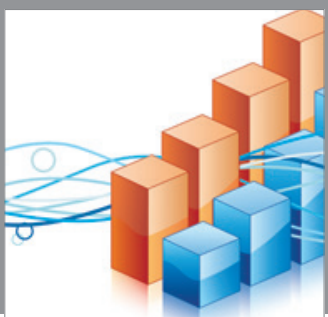

Advances in

Operations Research

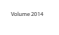

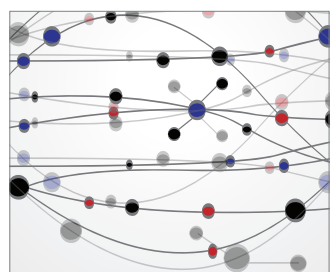

\section{The Scientific} World Journal
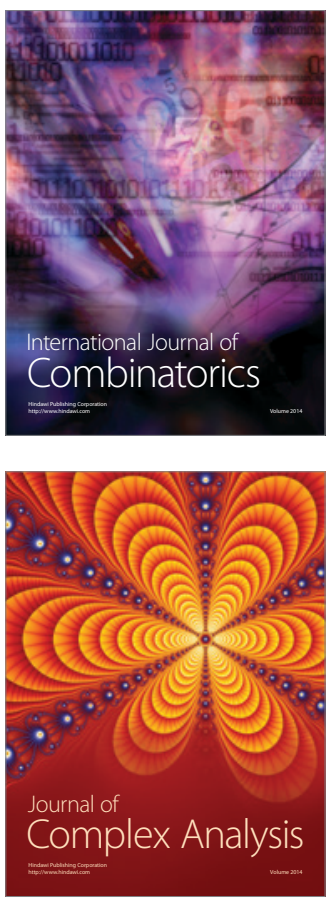

International Journal of

Mathematics and

Mathematical

Sciences
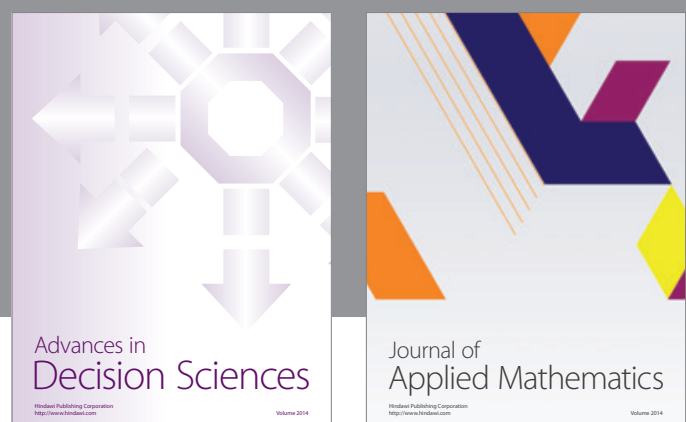

Journal of

Applied Mathematics
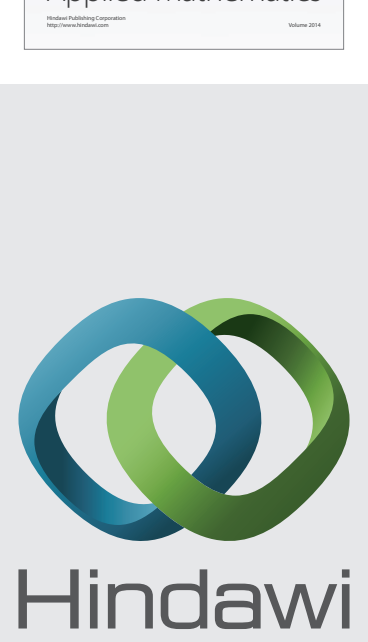

Submit your manuscripts at http://www.hindawi.com
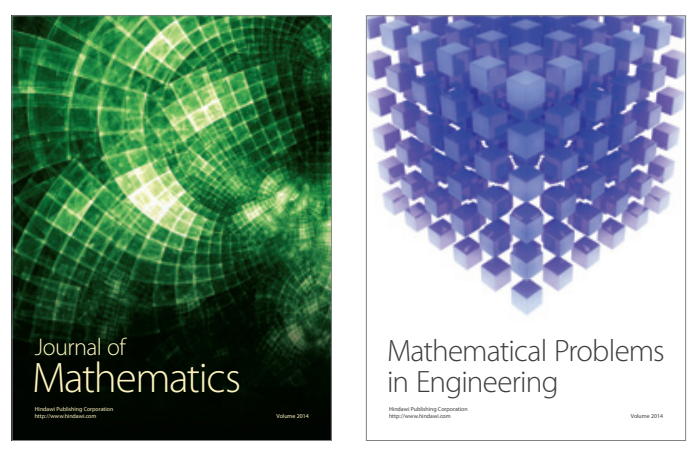

Mathematical Problems in Engineering
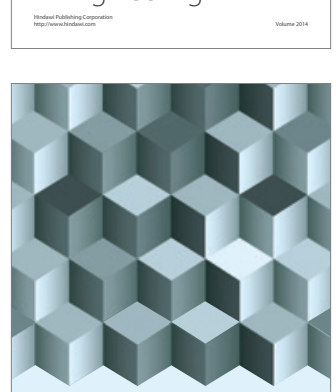

Journal of

Function Spaces
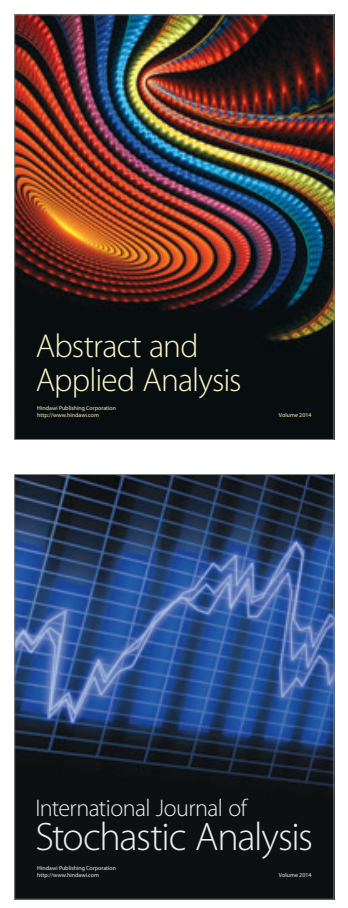

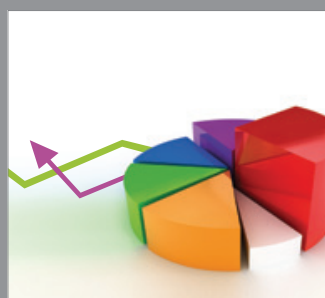

ournal of

Probability and Statistics

Promensencen
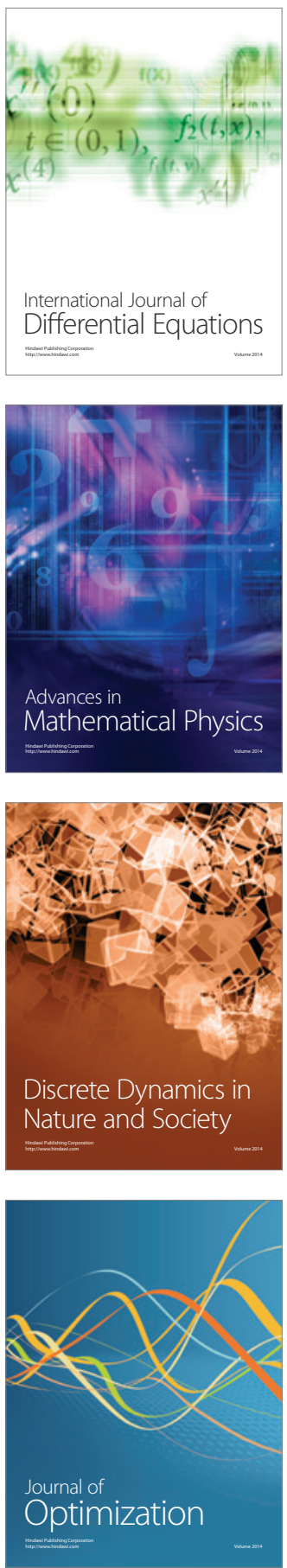